\title{
Perspective Choosing your poison
}

\author{
Harindra Karunatilake
}

Deliberate self harm or attempted suicide is a common medical admission to a general medical casualty in any given day. Everyday we find a new "poison" being used to harm oneself. It never ceases to amaze me the ingenuity of our general public in finding new ways "to kill" themselves. We come across self ingestion with intent to harm one-self with hair dyes, hair gels, detergents, plant catalysts, various therapeutic tablets, toilet cleaning liquids, and the list is endless. In 1995 third leading cause of death in state hospitals was agrochemical poisoning and it dropped to sixth place in 2006. Even though the case fatality rate has dropped the incidence of poisoning is increasing ever since. As in more developed countries we are moving from agrochemical poisoning to overdose with therapeutic drugs. When compared numbers of hospital admissions in 1988 and 2006 there is massive $678 \%$ rise in poisoning with therapeutic drugs (1).

Since of late we have seen many new substances are being used in deliberate self harm cases.

Some of these poisonings are fatal and some carries a high morbidity. I have chosen three of them to highlight the new trend. As practising clinicians we should be aware of the new "poisons" available, their effects in overdose and their potential antitoxins if any available.

First is Prinso. Prinso is a washing powder. A detergent manufactured in small scale without any form of quality assurance. It consists of two sachets, one containing pink crystals and the other white granules. One is containing $1 \mathrm{~g}$ of potassium permanganate $\left(\mathrm{KMNO}_{4}\right)$ and the other $10 \mathrm{~g}$ of oxalic acids. This is common in rural southern province (2). Common presenting features are mild to moderate epigastric burning, low urine output and high blood pressure. Its effects include hypocalcemia, acute renal failure, toxic to the gastric mucosa and metheamoglobineamia. Hypocalcemia is secondary to calcium oxalate crystal formation and renal toxicity. Ingestion of oxalic acid was associated with a higher case fatality ratio (CFR) while ingestion of both $\mathrm{KMNO}_{4}$ and oxalic acid was associated with a CFR of $9.8 \%$. Ingestion of more than one sachet was associated with a significantly higher risk of death (3). Significant number of patients believed to die before reaching a health facility (2). Given the short interval between ingestion and death, a cardiac cause is likely, possibly from severe hypocalcaemia. Oxalic acid poisoning has been clearly linked with acute renal impairment.

Prompt treatment with calcium salts, addressing the hydration issues and checking metabolic status with aid of arterial oxygen levels and correcting correctable elements is the current treatment strategy in the absence of evidence based therapy.

Another pesticide we see commonly since of late is abamectin. Abamectin is a pesticide recently introduced to the local market. Abamectin is a mixture of averrmectins. Human effects of avermectins are not clearly defined. Reported effects include fever, bone pain, pruritus, mydriasis, hypotension and tachycardia. In contrast to common organophosphate poisoning presented with cholinergic signs patients with abamectin poisoning present with dilated pupils, ataxia and confusion (4). The only available series describing patients with ingested abamectin observed nausea, vomiting, diarrhoea, drowsiness, agitation and weakness. Aspiration pneumonia was associated with adverse outcome. (4). Abamectin stimulates gama amino butyric acid (GABA) receptors in the central nervous system. Humans are less susceptible to its effects as it does not cross the blood brain barrier readily. Treatment is largely supportive. Gastric decontamination and use of activated charcoal is the mainstay. Securing the air way helps prevent aspiration. GABAergic drugs such as benzodiazepines should be avoided in acute setting. Neostigmine and flumazenil had not been useful.

Laslty penoxsulam, a new herbicide poisoning reported from Polonnaruwa. Penoxsulam is a fluorinated benzenesulfonamide. It is a herbicide used in dry and wet seeded crops mainly in rice paddies in Sri Lanka. Eye contact with penoxsulam dust or granules may cause slight irritation, although corneal injury is unlikely. Harmful effects are not anticipated from swallowing small amounts. Due to limited solubility in urine, penoxsulam forms crystals/calculi in the pelvis of the kidney and the lumen of the urinary bladder. Raised blood urea, reduced urine osmolality and increased urine volume were noted as secondary effects. Human intoxication with penoxsulam has been reported from Polonnaruwa (5). The patient developed acute renal failure requiring dialysis. It is important to be aware of the possible renal toxicity of this herbicide. Though it is not common yet we need to be aware of this as it is a completely reversible cause of acute renal failure.

As I mentioned before we see a new poison being tried every day. The toxic effects of most of them are not previously known. We should keep a record of these new 
agents and their toxic effects for future references. The poison information centre can trace the new trends and inform the physicians about the new "poisons", relevant symptoms and the antitoxins if available.

\section{References}

1. Fernando R poisoning a modern epidemic Sunday observer December 2008

2. Munasinghe $M$, Fernando $W$ : The toxic laundry powder "Prinso" is gaining notoriety amongst villagers for deliberate self-poisoning in and around the Matara district. Sri Lanka Journal of Critical Care 2009,1(1):29-30.
3. Gawarammana IB, Ariyananda PL, Palangasinshe C, de Silva NGL, Fernando K, Vidanapathirana M, et al.: Emerging epidemic of fatal human self poisoning with a washing powder in Southern Sri Lanka: A prospective observational study. Clin Toxicol (Phila) 2009,47(5):407-411

4. Karunatilake H. et al., (2012). Partial ptosis, dilated pupils and ataxia following abamectin poisoning. Ceylon Medical Journal. 57(3), pp.125-12

5. Karunatilake $\mathrm{H}$ Acute Renal Failure following Penoxsulam poisoning: Clin. Toxicol.2012; 50(1): 79 